\title{
Pairing Events Domain
}

National Cancer Institute

\section{Source}

National Cancer Institute. Pairing Events Domain. NCI Thesaurus. Code C102694.

A subject domain utilized for the submission of information encompassing and representing data, vocabulary or records related to pairing events. 